\title{
The Relationship Between Women Household Activity Hours and the Wage Gap Between Men and Women
}

\author{
Shengtong Wan ${ }^{1, \#, *}$, Yujie Li ${ }^{2, \#, *}$, Yi Ren ${ }^{3, \#, *}$ \\ ${ }^{1}$ High School Affiliated to Shanghai Jiaotong University, Shanghai, 200000, China \\ ${ }^{2}$ Bryn Mawr College, 101 North Merion Ave Bryn Mawr, PA, U.S \\ ${ }^{3}$ Capital Normal University High School, Beijing, 100048, China \\ \#The authors contributed equally to this manuscript \\ *Corresponding authorEmail: renyi_2022@163.com,jessieli1028@gmail.com,3137677768@qq.com
}

\begin{abstract}
This research paper is aimed to find the correlation between women's household activities hours and the gender wage gap. We gathered data from U.S. Bureau of Labor Statistic (BLS) and the World Bank. In this paper, we considered serval independent variables to control the data, in order to get the most accurate result. We are taking GDP, population growth and women's median annual wage to control the macro part, and taking women's working hours, education attainments, and labor force participation rate and fertility rate to control micro part. Using a multiple linear regression to determine the influence level of these eight independent variables on the dependent variable, which is the gender gap. Our results indicates that women's household activities hours are no significant to the gender wage gap. However, due to the lack of data and the minor flaw in the model, the result of this paper is not final. This topic still needs further research.
\end{abstract}

Keywords: Household Activities, Wage Gap, Relationship, Multiple Linear Regression

\section{INTRODUCTION}

In 1963, the United States passed the "Equal Pay Act" to achieve: when women and men are doing the same work, they will get the same salary [1]. Now, several decades have passed, women's overall wages are still not as high as men's. Women are usually face both working and domestic working pressure, but men are generally absent from most household activities. Traditionally, women are expected to undertake most of the housework, such as cooking, cleaning, and take care of the next generation of the family. Men are expected to do physical labor to earn income for the family. However, with the development of society, more and more jobs do not involve physical labor anymore. More women started to become valuable workforce to the society. When women become compatible workforce as men in the labor market, the domestic work responsibility is still most likely falls on women's shoulders.

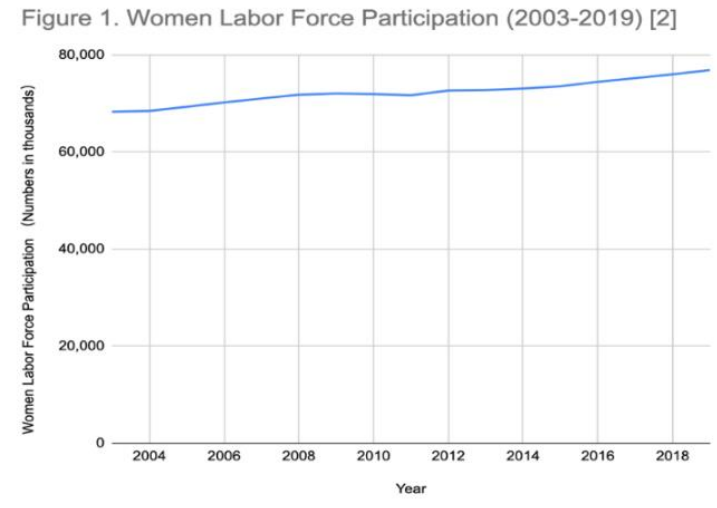

Figure 1 Women Labor Force Participation (2003 2019) [2]

There are several logics that may explain the negative correlation between women's housework hours and the women's wage. First, women are more willing to do the housework, due to the "gender role" that have ben implemented in mostly everyone when their young. Plus, only women can pregnant, deliver, and nurse the children, which gives them a deeper connection with their children. Thus, women are more willing to "sacrifice" their work time and devote their time on family. In that case, married 
women or a mother will tend to choose a job that is gentle on workload and flexible on schedule. Obviously, these types of work's salary will be lower than a high-pressure work. Also, the housework's effect on women's mental health and employer's bias towards married women are all possible reasons to explain the housework hours and the gender wage gap.

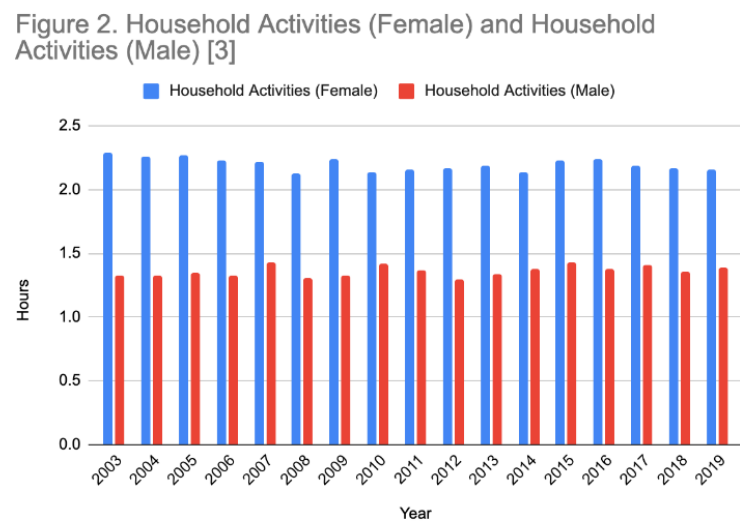

Figure 2 Household Activities (Female) and Household Activities (Male) [3]

This article will try to find the correlation between women's household activity hours and the wage gap between men and women. We want to find out how domestic work becomes a penalty to women's wages. We will conduct a literature review to establish a general understanding of why women often take more housework than men. Is there any evidence to show that the inequality in household activity distribution is the origin of the gender wage gap? Then, in the data and methodology section, we will use $t$ test and regressions to build a model to figure out the relationship between domestic working hours and the gender wage gap.

\section{LITERATURE REVIEW}

\subsection{Why Women often do most of the housework?}

The question of this research paper will begin with why the household activity is inequality distributed among gender. The research conducted by Becker suggests that in order to maximize the utility of the family, the members of the family must work together in a division of labor, and each specializes in areas of their advantages [4]. Since family members have their own strengths in different labor, the division of labor in the family is just like the division of labor in the labor market where the individual's abilities can be used in maximum. Women have an absolute advantage in domestic work, largely due to their mothers' roles. They are more concerned about housework and caring for children compare to men. Men are more market-oriented, which means they pay more attention to the labor market. Thus, men have an advantage in earning income. The husband's advantage in the labor market, such as his high education level and high income, determines that he is less engaged in housework. Therefore, the new family economics uses the theory of "comparative advantage" of men and women to explain the time allocation of married women.

In addition, there are gender differences in attitudes towards housework, which is a reason for the gender division of housework that cannot be ignored. Men and women have been socialized by established "gender roles" since they were young, which makes them internalizing mainstream gender awareness, and forming appropriate gender roles when they enter the society. These appease attitude toward gender awareness undoubtedly caused the unevenly distribution of housework. Daily housework and childcare are often regarded as women's work, and this belief has become a symbol of gender identity [5]. For example, women may think that doing traditional housework after marriage is a symbol of their being more feminine or that a tidy home can better display their image as a good wife. As a result, women have a positive attitude towards housework, and they prefer to do housework and take care of children more than men. Therefore, although the gender division of housework is not equal in dual-income families, most wives and husbands believe that such a division of labor is fair [6], and it is the difference in attitudes towards housework that leads to the gender division of housework.

\subsection{Possible theory regarding the relationship between hah and wage gap}

First of all, people with family responsibilities tend to choose "easier" jobs and get lower wages, and they even become lack of interest in market work. For example, Hersch found in her research that women spend more time on housework than men, and women are more inclined to choose comfortable and safe jobs [7]. In addition, family responsibilities, especially daily housework and childcare activities, have resulted in unfree time allocation. Thus, women with greater family responsibilities may strictly lock their job search process to a shorter commuting time or flexible arrangements. Some women may choose to suspend their work and dedicate all of their time in their family. Becker believes that the more time and energy invested in family labor, the less energy and time invested in the labor market, which will affect performance in the labor market [8].

The research about women household activity hours affects the gender wage gap has many obstacles, because many variables that actually have an impact on gender wage gap is not measurable. For example, Becker's theory includes the "performance in the labor market", and there is no way to quantify the performance level of a women in the market. There are more variables that are important to this research but hard to measure, such as effort level of work, attention on work, and employer's bias. 
Moreover, the causal relationship between housework hours and wage remains unclear, because high wage will empower women a higher bargaining power in terms of housework [9]. If a woman is able to earn high wage in the labor market, she can use this as a "bargaining chip" to talk with her husband and demand less housework time. Thus, it is hard to find the true correlation between woman housework hours and gender wage gap.

\section{DATA AND METHODOLOGY}

In this section, we investigate in whether the time women spent on housework every day will contribute an influence on women's wage as a percentage of men's by utilizing the regression model. Taking the integrity and reliability of the data into consideration, we settled down on the United States as our study area.

\subsection{Changes and the Initial design}

We chose 7 variables and our dependent variable, which is women's earning as a percentage of men's, and the independent variable we are interested in investing in, which is women's housework hours, to come closer to ceteris paribus. We had variables that control the macro scale of the economy in the U.S, such as the GDP, and variables that control the situation of an individual, such as the Fertility rate.

Table 1. Variables included in the regression model

\begin{tabular}{|c|}
\hline DP \\
\hline Population growth (annual \%) \\
\hline Total Women's Median Annual Earnings (Dollars) \\
\hline $\begin{array}{l}\text { Educational attainment, at least completed upper } \\
\text { secondary, population } 25+\text {, female }(\%)\end{array}$ \\
\hline $\begin{array}{l}\text { Women Labor Force Participation ( Numbers in } \\
\text { thousands) }\end{array}$ \\
\hline Fertility rate in U.S (how many births per woman) \\
\hline Working and work-related activitie \\
\hline
\end{tabular}

Table 1 shows the variables which we think have effects on the wage gap between men and women. Since there are have more than two independent variables, this research uses a Multiple Linear Regression Model to predict dependent variable by using several independent variables. The goal of this research is to find the linear relationship between the independent variables and the dependent variable. The following shows the equation:

$$
\begin{gathered}
\gamma=\beta_{o}+\beta_{1} x_{1}+\beta_{2} x_{2}+\beta_{3} x_{3}+\beta_{4} x_{4}+\beta_{5} x_{5}+\beta_{6} x_{6} \\
+\beta_{7} x_{7}+\beta_{8} x_{8}
\end{gathered}
$$

In this equation, $y_{i}$ represents the dependent variable, which is the annual percentage growth of women's earnings as a percentage of men's while all the $x$ represents the dependent variables in Table1.

All the variables' data in table 1 are collected from the World Bank (https://www.worldbank.org/en/home), which is guarantees the reliance and the accuracy of the data. As for the dependent variable, we found the data from U.S Bureau of Labor Statistics [https://www.bls.gov/]. Since, this is the data that released from the official website, we believe that the survey was trustworthy, and the Effect of Large Numbers will cover the individual mistakes in such national surveys leaving us with a result rather close to reality.

After doing a test run of the regression, we found that the p-value are too high to have any statistical conclusions which is not acceptable even though the $\mathrm{R}$ Square is in an ideal value. Since our data of housework hours is very limited by the year $(2003-2019)$, having only 16 samples in the regression might be the reason of high $p$ value. Therefore, we divided the hour spent on housework into different categories to expand the sample size for a better p-value (See table 3 ). We changed the data into panel data and this enables us to have 170 observations which increases the accuracy. Table 2 shows the subdivision categories of household activities that we used to create a set of panel data.

Table 2. The subdivision categories of household activities

\begin{tabular}{|l|}
\hline Housework \\
\hline food preparation and cleanup \\
\hline lawn and garden care \\
\hline household management \\
\hline interior maintenance, repair, and decoration \\
\hline exterior maintenance, repair, and decoration \\
\hline animals and pets \\
\hline vehicles \\
\hline appliances, tools, and toys \\
\hline travel related to household activities \\
\hline
\end{tabular}




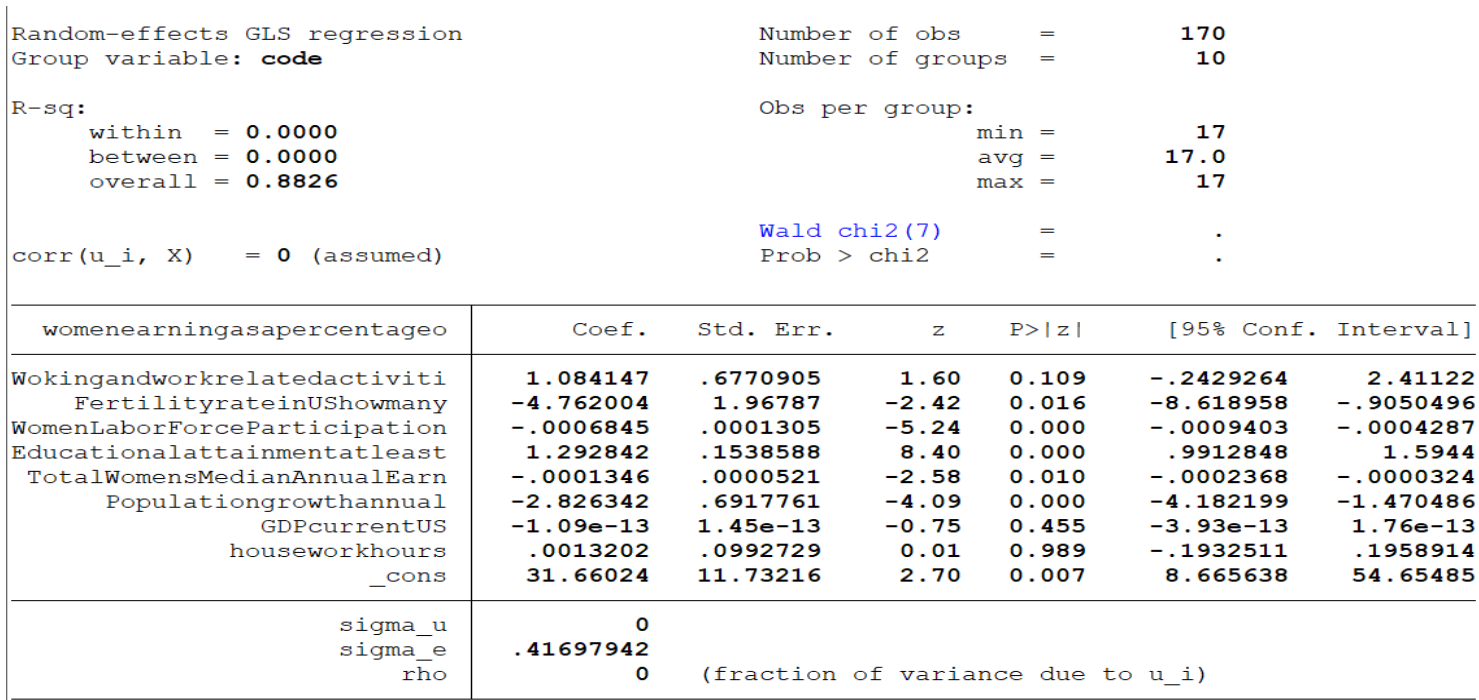

Figure 3 Regression Result with the Expanded Women Household Activities

When discussing with Professor David Parsley, we realized that some of our variables are in the form of percent change such as the population growth and the education attainment which means we are comparing things that don't even match with each other and it is hard for us to explain our results from the regression. Therefore, we converted all of our variable into the form of annual percent change in order to get a clearer understanding.

\subsection{Hausman test}

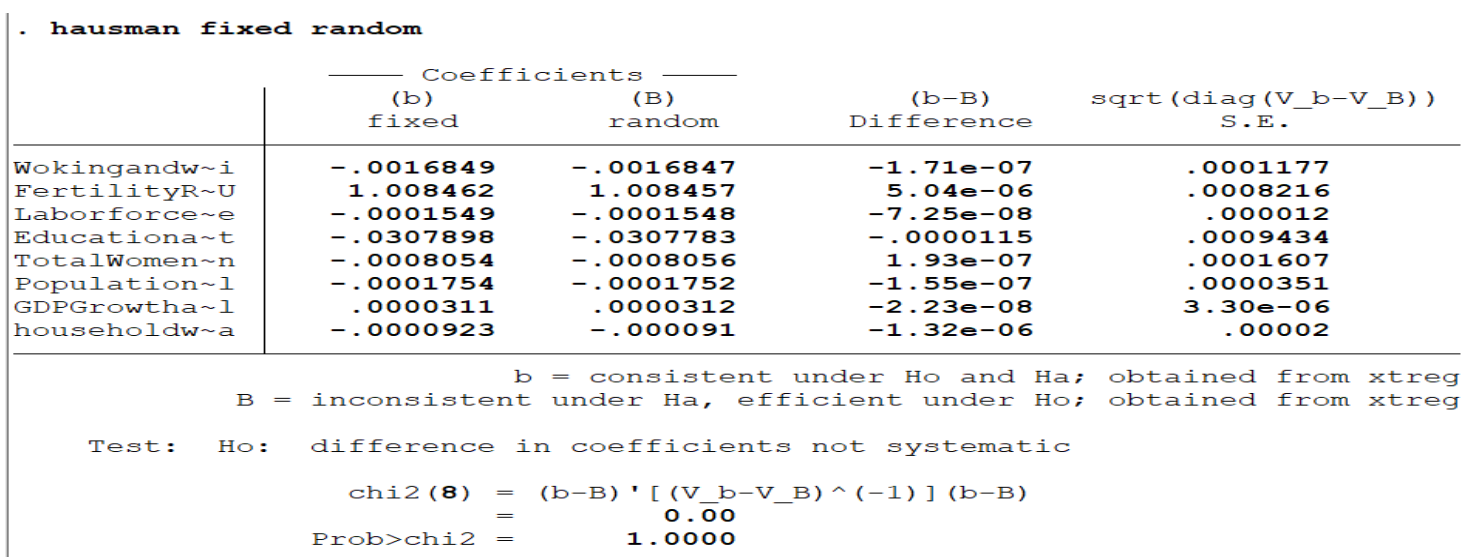

Figure 4 Hausman Test result -
Since there are two different types of multiple regression dealing with panel data, the fixed effects model and the random effects model, we need to decide which model fits our model the most. In order to check the Model Fit, we ran the Hausman Test to evaluate whether to use a fixed effects model or a random effects model. (Hausman tests (Hausman 1978) are tests for econometric model misspecification based on a comparison of two different estimators of the model parameters)

The results of the Hausman Test shows that we cannot reject the null hypothesis which means that the random effects model fit our case the best. 


\subsection{Regression results}

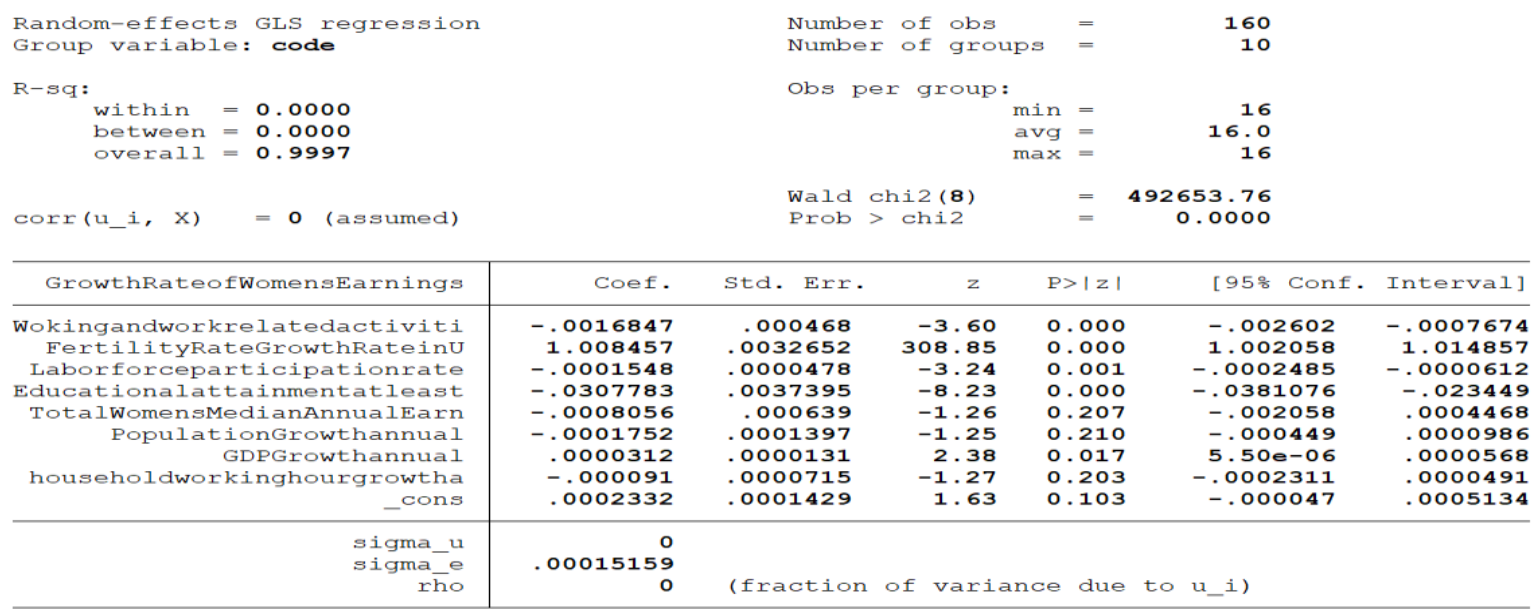

Figure 5 Final Regression Results

The following is the equation we concluded from the results of the regression:

Growth Rate of Women's Earnings as a Percentage of Men's(annual\%) $=0.002332+(-0.0016847) x_{1}+1.008457 x_{2}+(-0.001548) x_{3}+(-0.307783) x_{4}$ $+(-0.0008056) x_{5}+0.0001752 x_{6}+0.0000312 x_{7}+(-0.000091) x_{8}$

In this equation, we have Working and work-related activities (female annual \% change) as xi1 , Fertility Rate Growth Rate in U.S (how many births per woman, annual \%) as xi2, Labor force participation rate, female (annual \% change) as xi3, Educational attainment, at least completed upper secondary, population $25+$, female (annual \% change) as xi4, Total Women's Median Annual Earnings Growth (annual \%) as xi5 , Population Growth (annual \%) as xi6, GDP Growth(annual \%) as xi7 , and household working hour growth (annual \%) as xi8.

\section{EMPIRICAL RESULTS AND DISCUSSION}

Based on the third part of the paper, R-square is 0.9997 , which means $99.97 \%$ of the relationship between variables and women's earnings as a percentage of men can be explained by the Random Effects Model (REM). Therefore, the model is exceedingly valuable.

In the model, the $p$ values of household working time growth are greater than 0.1 , which indicates these three variables do not have relationships with wage gap. The possible reason is that even though women spend longer time doing household activities, they could still fully concentrate on their work by sacrificing the amount of time on other activities like sleep. Besides, for the growth of total women median annual earning and annual population growth as independent variables, both of their $\mathrm{p}$ values are greater than 0.1 . The result suggests that the change rate in women annual earning and population growth rate have little impact on the wage gap.

The $p$ value of annual GDP growth is less than 0.05 and greater than 0.01 , and its regression coefficient is greater than 0 . This suggests that GDP growth has a positive impact on the wage gap. Even though we know that consumption increases as income increases and $\mathrm{GDP}=\mathrm{C}+\mathrm{I}+\mathrm{G}+\mathrm{NX}$, other factors could affect GDP, and we cannot learn about different performance between men and women. As a result, in order to find how GDP growth affects the Growth of wage gap, we need more research in the future.

The $p$ values of working and work-related activities, fertility rate, women labor force participation, education attainment are less than 0.001 , so all of those four variables have an extremely significant effect on women's earnings as a percentage of men (the wage gap between men and women). The coefficient of working and work-related activities is negatively related to the growth of women's earnings as a percentage of men's because spending more time on work provides more productivity. Thus, productivity of a woman can be considered equally to that of a man. Since the company is willing to complete projects timely, the wage gap is a kind of an insurance that a company wants to keep benefits. According to regression, the annual growth of fertility rate significantly has a positive relationship with the wage gap between men and women. A $1 \%$ increase in fertility rate will lead to a $1.008 \%$ increase in the wage gap, which means these two have a nearly perfect positive correlation. The reason is that the high fertility rate causes the average time a woman spends taking care of their children or going on maternity leave to become greater. Comparing with a male, every female is more likely to spend less time on their work, so the productivity per female is less than that of a male. Moreover, a negative correlation between the growth of women's labor force participation between women's earnings as a percentage of men's is shown, the increase of female labor force 
participation reduces the wage gap between men and women. However, due to the change of the labor market, we do not know whether the growth of women's labor force participation influences the growth of women's unemployment rate. Also, we do not consider the growth of men's labor force participation as a variable in this paper, so we fail to find the detail of how women labor force participation affects the wage gap, it needs further exploration. The relationship between at least complete upper secondary learning and women's earnings as a percentage of men's is negative. Due to the reason of the different physiological characteristics of men and women, men with low education attainment, for instance, men who fail to graduate in high school, can engage in manufacturing, mining, smelting, and other highintensity manual work. Comparatively, women with the same educational attainment can only be limited to the life service industry, in other words, women's employment orientation is much narrower than men's. And the improvement of education background will broaden women's choice of work, help women get into the Internet, finance, and other high-paying industries.

To sum up, comparing with Hersch, J.'s research result, we focus on longer time in order to find a more subjective law between household working time and wage gap. Plus, we use different methods to explore the relationship, so this could lead thought to different results. Therefore, the correlation between home production and the wage gap needs more data like 30 years' observation, which will better show the long-term relationship. In this case, researchers will be able to estimate future trends.

\section{CONCLUSION}

This research paper is meant to find the correlation between women's household activities hours and the gender wage gap. Our final regression result shows that the coefficient of the percent change of women's housework hours variable is -0.00091 with the $\mathrm{P}$ value 0.203. This result shows that there is a negative correlation between women's housework hours and the gender wage gap. Although the $\mathrm{p}$ value shows the correlation between the women's housework hours and dependent variable is not as significant as the other independent variables, it cannot reject the negative correlation between them, because the model and data are not perfect.

Although we choose the most reliable sources for data in this paper. There may still have some flaw in our model. We cannot quantify the employ's bias towards women on the job interview. Also, we are unable to collect data regarding women's mental health. There are many more variable in real life scenarios that may influence the gender wage gap, and these factors needs further explore.

\section{REFERENCES}

[1] Sweet, J. (2021, March 8). History of women in the workplace. Stacker. https://stacker.com/stories/4393/history-womenworkplace.

[2] FRED. (2021, July 2). Labor force participation rate - $\quad$ women. https://fred.stlouisfed.org/series/LNS11300002\#0.

[3] U.S. Bureau of Labor Statistics. (2017, June 27). Table A-1. time spent in detailed primary activities and percent of the civilian population engaging in EACH detailed primary ACTIVITY Category, averages per day by Sex, annual AVERAGES, TOTAL. U.S. Bureau of Labor Statistics. https://www.bls.gov/webapps/legacy/tusa_1tab1.ht $\mathrm{m}$.

[4] Happel, S. K., \& Becker, G. S. (1983). A treatise on the family. Journal of Marriage and the. Family, 45(1), 231. https://doi.org/10.2307/351313

[5] Bianchi, S. M., Milkie, M. A., Sayer, L. C., \& Robinson, J. P. (2000). Is anyone doing the. housework? Trends in the gender division of household labor. Social Forces, 79(1), 191. https://doi.org/10.2307/2675569

[6] Poortman, A.-R., \& van der Lippe, T. (2009). Attitudes toward housework and child care and the gendered division of labor. Journal of Marriage and Family, 71(3), 526-541. https://doi.org/10.1111/j.1741-3737.2009.00617.x

[7] Hersch, J. (1991). The Impact of Nonmarket Work on Market Wages. he American Economic Review,81(2), 157-160. Retrieved August 5, 2021, from http://www.jstor.org/stable/2006845

[8] Becker, G. S. (1985). Human capital, effort, and the sexual division of labor. Journal of Labor Economics, 3(1, Part 2). https://doi.org/10.1086/298075

[9] Bittman, M., England, P., Sayer, L., Folbre, N., \& Matheson, G. (2003). When Does Gender Trump Money? Bargaining and Time in Household Work. American Journal of Sociology ,109(1), 186-214. doi:10.1086/378341

[10] Hersch, J. (2009). Home production and wages: Evidence from the American time use. survey. Review of Economics of the Household, 7(2), 159178. https://doi.org/10.1007/s11150-009-9051-z

[11] Baffes, J., Gul, M., \& Kitzmueller, L. (2021, August 4). World bank open data. Data. https://data.worldbank.org/. 